\title{
Effect of Chemical Enhancing-Technology on the Properties of Recycled Aggregate
}

\author{
Ping Li, ${ }^{1,2}$ Dongmei Zhang $\mathbb{D}^{1,3}{ }^{1,3}$ Di Wei, ${ }^{1}$ Jianping Xiong, ${ }^{4}$ and Jing Li ${ }^{1}$ \\ ${ }^{1}$ School of Traffic \& Transportation Engineering, Changsha University of Science \& Technology, Changsha 410114, Hunan, China \\ ${ }^{2}$ National Engineering Laboratory of Highway Maintenance Technology, Changsha University of Science \& Technology, \\ Changsha 410114, Hunan, China \\ ${ }^{3}$ Hunan International Scientific and Technological Innovation Cooperation Base of Advanced Construction and \\ Maintenance Technology of Highway, Changsha University of Science \& Technology, Changsha 410114, Hunan, China \\ ${ }^{4}$ Guangxi Transportation Science and Technology Group Co., Ltd., Nanning 530007, Guangxi, China
}

Correspondence should be addressed to Dongmei Zhang; dmzhang@csust.edu.cn

Received 21 May 2020; Revised 6 July 2020; Accepted 13 July 2020; Published 31 July 2020

Academic Editor: Fan Gu

Copyright (C) 2020 Ping Li et al. This is an open access article distributed under the Creative Commons Attribution License, which permits unrestricted use, distribution, and reproduction in any medium, provided the original work is properly cited.

\begin{abstract}
Strengthening the attached old cement mortar of recycled aggregate (RA) is a common approach to enhance the RA properties. In this study, four representative chemical enhancing-technologies were chosen. Through the analysis of physical properties, mechanical properties, and shape indexes, the changes of performance before and after strengthening were tested, so as to grasp the influence of chemical enhancing-technologies on the performance of RA. The results indicated that the chemical strengthening methods had obvious influence on the physical properties of RA, such as density and water absorption. Due to the different chemical enhancing mechanism, the influence trend and range were varied. The mechanical properties of RA such as crushing value and abrasion value were obviously improved by chemical enhancement. However, chemical enhancement had an effect on the shape of RA, which will slightly reduce the angularity index and sphericity index. The texture index of RA with C-3 and C-7 decreased sharply, but texture index increased after abrasion, and the discrepancy of aggregate texture index of different enhancing methods is significantly reduced. The microanalysis exhibited that the aggregate surface structure with $\mathrm{C}-3$ and $\mathrm{H}$ was large, but there were a lot of fine structures on the aggregate surface with C-7 and N-P. Different chemical enhancing methods have different effects on the mechanical performance and microstructure of RA, but it should be noted that the fluctuation of RA performance tends to increase.
\end{abstract}

\section{Introduction}

With the rapid development of infrastructure construction in China, a large number of old buildings have been demolished and rebuilt, and cement concrete pavement has been reconstructed, resulting in a large number of waste concrete. Replacing the aggregate of new road surface with this construction and demolition (C\&D) waste can not only alleviate the damage to the ecological environment caused by the stacking of C\&D waste, but also reduce the cost of road construction and the exploitation of natural stone, which has significant economic and social benefits. Compared with natural aggregate, the porosity [1], water absorption [2], and crushing value [3] of recycled aggregate (RA) increase, and microcracks will be produced in the process of crushing, which limit the application and development of RA. In order to make the RA have excellent performance, it is necessary to strengthen the RA $[4,5]$. The strengthening process mainly includes physical enhancing-technology [6-8] and chemical enhancing-technology, which are mainly to remove or enhance the weak cement mortars on the aggregate surface to improve its physical property. The chemical enhancing-technology is widely used because of its simple operation, low equipment requirements, no damage to the grading, and good strengthening effect. 
At present, the main technology used in the chemical enhancing is acid strengthening, polymer emulsion strengthening, pozzolanic cement mortar strengthening, sodium silicate strengthening, and carbonization strengthening. Acid solution can remove the cement mortar on the aggregate surface, thereby enhancing the aggregate performance. Tam et al. [9] prepared a certain concentration of hydrochloric acid, sulfuric acid, and phosphoric acid solution and washed out the cement mortar on the surface of RA, so that the water absorption of RA after enhancing decreased obviously. Kim et al. [10] selected sulfuric acid and hydrochloric acid to remove the cement mortar, which had a good effect on aggregate density, water absorption, and solid volume percentage. The polymer emulsion has good adhesive properties and can solidify in a short time to improve the quality of mortar; for instance, polyvinyl alcohol emulsion and silane-based polymer can fill the pores of the adhesive mortar and seal the surface of the RA. Kou and Poon [11] employed polyvinyl alcohol solution of different concentrations to soak the RA, which reduced the water absorption of the aggregate. Spaeth and Tegguer [12] adopted siloxane and silane-based polymer solution to soak the RA, which improved the water absorption and crushing resistance of the aggregate. Liu et al. [13] found that silane molecules diffuse to the micropores on the surface of RA, forming hydrophobic silicone film on the surface of aggregate, reducing its surface free energy and making more cement mortars gather around the adjacent recycled aggregate; thus, a larger binding area was formed to improve the strength. Guo et al. [14] secreted organosilicon waterproofing agent to chemically enhance the $\mathrm{RA}$ and verified that $48 \mathrm{~h}$ immersion treatment of organosilicon waterproofing agent had the best strengthening effect. Pozzolanic cement mortar can fill the pores and voids in the mortar and react with calcium hydroxide to form C-S-H (calcium silicate hydrate) gel [15], thus plugging the void of RA, bonding internal cracks, and improving the density and strength of RA. Chen [16] used two cement mortars enhancing methods (10\% silica fume and $30 \%$ fly ash) to strengthen the RA, which can improve the density and reduce the water absorption and crushing value of RA. Shaban et al. [17] proposed that the enhancing-technology of pozzolanic cement mortar (fly ash, silica fume, and nanosilica fume) can improve the performance of RA by strengthening weakly binding mortar. Sodium silicate solution can react with calcium hydroxide to form C-S-H gel [18], thereby improving aggregate functions. Spaeth and Tegguer [12] found that sodium silicate solution can reduce the water absorption of RA. Chen et al. [19] soaked the RA with different concentrations of sodium silicate solution and verified that the optimal concentration was $5 \%$, with $1 \mathrm{~h}$ soaking. Carbonation strengthening is based on the interaction of calcium hydroxide and calcium silicate hydrate on aggregate surface with carbon dioxide to form solid calcium carbonate in a relatively short period, thus strengthening aggregate performance. Zhan et al. [20] carbonized the RA with carbon dioxide and discovered that the water absorption and porosity decreased by $19 \%-25 \%$ and $18 \%-$ $21 \%$, respectively. Shi et al. [21] treated RA with carbon dioxide and spotted that it had better effect on reducing water absorption improving fluidity. Moro et al. [22] analyzed the impact of nano- $\mathrm{TiO}_{2}$ on recycled mortars properties, and their results showed that the addition of nano- $\mathrm{TiO}_{2}$ increases compressive and flexural strength of recycled mortars under normal conditions $\left(20^{\circ} \mathrm{C}\right)$. Kumar [23] used a calcium hydroxide solution to precoat the surface of recycled fine aggregates in order to activate blast-furnace slag incorporated in recycled fine aggregate mortar to enhance performance.

Scholars at home and abroad have carried out massive researches on chemical enhancing of RA. However, due to the differences in the properties of raw materials, there are significant differences in the performance of RA. There are relatively few comparative studies on the effects of different chemical strengthening methods. Nevertheless, there are few studies on the effect comparison of different chemical enhancing-technology. In this study, four enhancing-technologies were selected to strengthen the RA in pavement overhaul engineering, and the strengthening effects of different chemical enhancements were compared. The enhancing mechanism was analyzed by testing the physical index, mechanical index, and shape index.

\section{Experimental}

\subsection{Materials}

2.1.1. Recycled Aggregates. The RA is limestone, which is selected from the crushed waste cement concrete of a high speed pavement overhaul project, processed into aggregate by jaw crusher, and then screened into $0 \mathrm{~mm}-5 \mathrm{~mm}$ and $5 \mathrm{~mm}-19 \mathrm{~mm}$. This paper mainly tests the performance of $5 \mathrm{~mm}-19 \mathrm{~mm}$ recycled coarse aggregate, as illustrated in Figure 1.

2.1.2. Chemical Enhancers. In this study, cement, first-class fly ash, sodium hydroxide $(\mathrm{NaOH})$, polyvinyl alcohol (PVA), and sulfuric acid $\left(\mathrm{H}_{2} \mathrm{SO}_{4}\right)$ were selected as chemical enhancers.

2.2. Testing Methods. As shown in Figure 2, chemical enhancing-technologies of RA were analyzed from two aspects of enhancing effect and enhancing mechanism.

2.2.1. Chemical Enhancing-Technologies. We employed four representative processes to enhance the $\mathrm{RA}$, which are $\mathrm{C}-3$, C-7, N-P, and H. C-3 and C-7 are strengthened by filling surface voids with cement mortars after immersion and repairing microcracks. N-P method uses alkali solution to corrode cement mortars, while polyvinyl alcohol can seal and cover the surface of RA to strengthen. $\mathrm{H}$ method is to use acid liquid chemical reaction to remove surface mortar to strengthen. The materials and technologies are shown in Table 1. 


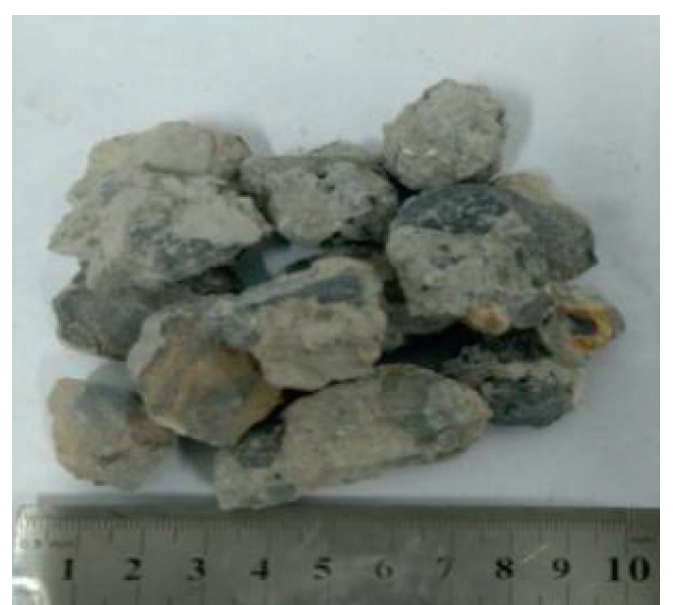

Figure 1: Recycled coarse aggregate.

2.2.2. Physical Property Test. According to the Test Method of Aggregate for Highway Engineering (JTG E42-2005), the apparent density, water absorption, crushing value, and abrasion value of RA were examined.

2.2.3. AIMS. Aggregate imaging measurement system (AIMS) can obtain objective morphological properties of aggregate such as angularity, texture, and sphericity. Three kinds of aggregates with particle size of $19 \mathrm{~mm}, 9.5 \mathrm{~mm}$, and $4.75 \mathrm{~mm}$ were selected as the test objects.

2.2.4. SEM. Scanning electron microscopy (SEM) was chosen to evaluate the microsurface appearance of RA. The aggregate with the particle size of $4.75 \mathrm{~mm}$ after enhancing was taken as the observation object, with the 500 times magnification.

\section{Results and Discussion}

3.1. Apparent Density. The appearance of RA after chemical enhancement is shown in Figure 3. It can be seen that the aggregate surface has changed significantly. The surface of RA treated by C-3 method (Figure 3(a)) was coated with a layer of cement mortars, and the surface was smooth. Compared with C-3 method, the cement mortars on the surface of RA treated by C-7 method (Figure 3(b)) were thicker, and the color was lighter. Meanwhile, after enhancing by N-P method (Figure 3(c)), the RA surface was clean, and film-like substances can be observed on the uneven surface of some large particles. After $\mathrm{H}$ method (Figure 3(d)), part of the cement mortars on the RA surface fell off and the looked rough.

The effect of chemical enhancement on the average value of apparent density of RA is revealed in Figure 4. After treating by C-3 method, the apparent density was reduced, which was due to the insufficient hardening of cement mortar coated on the surface and the existence of voids. As the curing time was prolonged and the hardening was sufficient, the apparent density of RA after C-7 method was greatly increased. Owning to chemical reaction, the density of RA treated by N-P method was increased simultaneously. Besides, the density of RA after $\mathrm{H}$ method was also increased, which was more likely due to the corrosion of the cement mortar on the RA surface.

The maximum difference of RA density with different particle sizes is $0.048 \mathrm{~g} / \mathrm{m}^{3}$. In the $\mathrm{C}-3$ method, the maximum difference of the density of different particle size RA is $0.121 \mathrm{~g} / \mathrm{m}^{3}$. It was found that, after chemical enhancement, the density dispersion degree of RA with different particle size increased obviously. Due to the uneven coverage of cement mortars and inadequate curing, C-3 method had the greatest influence on the increase of RA density dispersion. After the enhancement of N-P method and $\mathrm{H}$ method, the material distribution on the surface of RA was nonuniform, which resulted in the uneven chemical reaction, thereby the increasing of density dispersion.

It illustrated that when the chemical enhancing-technology was used to treat RA in engineering, we should pay more attention to the control of RA property fluctuation after enhancing. The reason for the difference of apparent density of RA with different particle sizes is that the content and state of cement mortars on the surface of aggregates are different.

3.2. Water Absorption. The chemical enhancement has a significant effect on the water absorption of RA as shown in Figure 5. The water absorption of RA after C-3 method and $\mathrm{C}-7$ method was increased because the aggregate surface was coated with hardened cement mortar, which owned strong water absorbing quality, and the water absorption capacity became stronger with the prolongation of curing time. The decrease of water absorption of $\mathrm{RA}$ after N-P method was due to the formation of network structure on the surface by the PVA polymer and the chemical reaction between active functional group and aggregate surface, forming the framework of hydration product. Then, the surface of RA is bonded by the network structure to form a layer of hydrophobic film, thereby reducing the water absorption [24]. Because $\mathrm{H}_{2} \mathrm{SO}_{4}$ can corrode the cement mortar, which had a high water absorbing ability, the water absorption of RA treated by $\mathrm{H}$ method was decreased [25].

The analysis testified that the enhancement had a palpable influence on the dispersion degree of water absorption of RA with different particle size. The dispersion degree of water absorption of RA treated by C-3 and C-7 method was significantly increased. Due to the different surface area of RA, the amount of cement mortar coated on the surface was totally different, while the water absorption of hardened cement mortar was large, resulting in the fluctuation of water absorption of RA after chemical enhancement. On the contrary, the water absorption of RA with different particle size treated by N-P method and $\mathrm{H}$ method had little change. The main reason for the difference in the influence trend of water absorption of RA with different particle sizes is that the content and state of cement mortars on the surface of aggregates are different. 


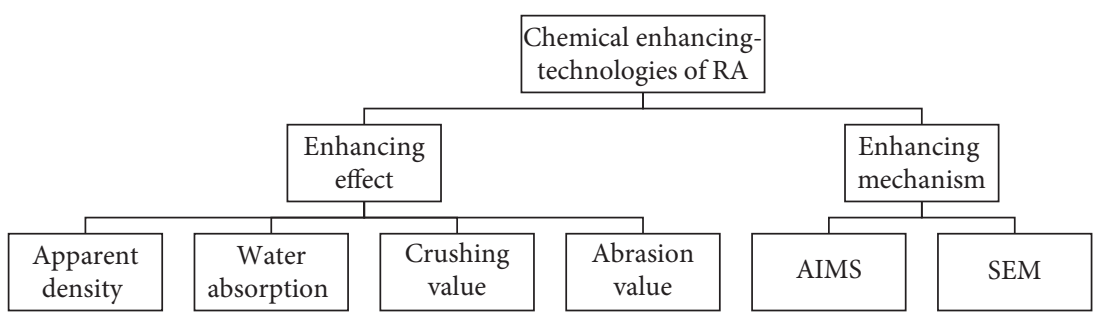

Figure 2: Technical route of this research.

TABLE 1: Chemical enhancing materials and technologies.

\begin{tabular}{lcc}
\hline Methods & Materials & Technologies \\
\hline C-3 method & Cement : fly ash:water $=8: 2: 10$ & Soak for 60 min and air-dry for 3 days (at room temperature) \\
C-7 method & Cement: fly ash: water $=8: 2: 10$ & Soak for 60 min and air-dry for 7 days (at room temperature) \\
N-P method & Solution: $\mathrm{NaOH}(0.57 \%) / \mathrm{PVA}$ & Soak in $\mathrm{NaOH}$ and PVA for 1 day, respectively, and then air-dry (at room temperature) \\
$\mathrm{H}$ method & $(2 \%)$ & Soak in $\mathrm{H}_{2} \mathrm{SO}_{4}$ forl day, and then air-dry (at room temperature) \\
\hline
\end{tabular}

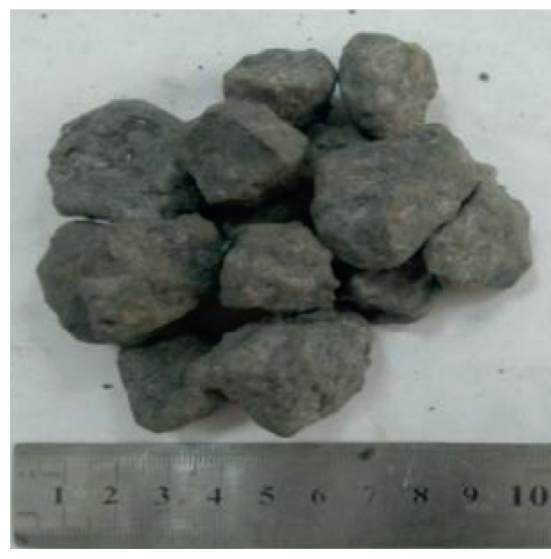

(a)

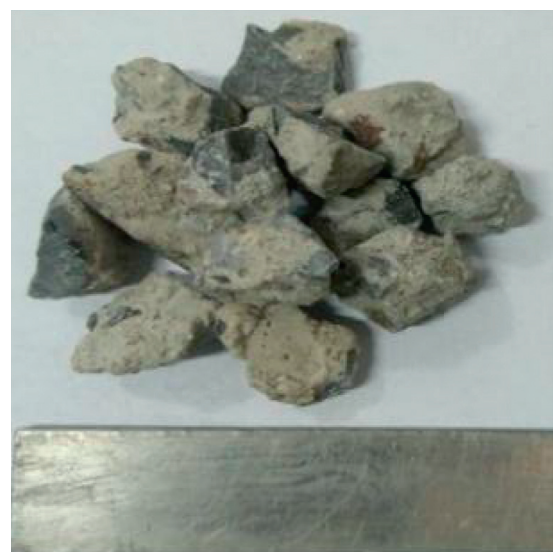

(c)

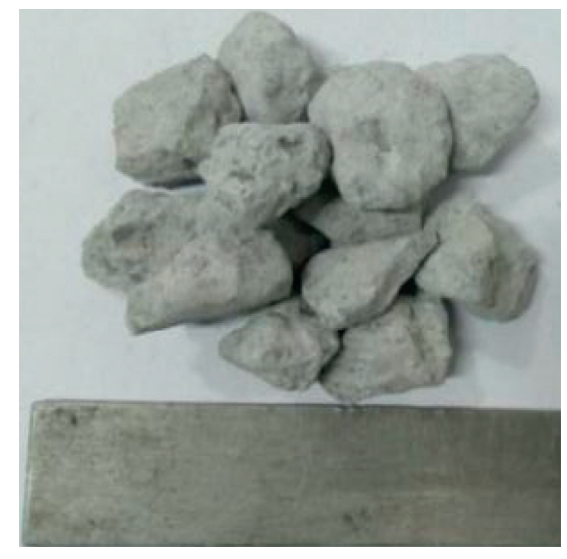

(b)

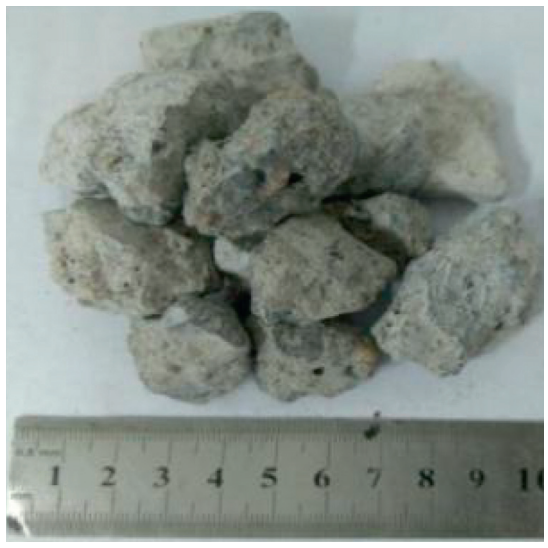

(d)

FIgURE 3: Appearance of RA after chemical enhancing-technology. (a) C-3 method. (b) C-7 method. (c) N-P method. (d) H method.

3.3. Crushing Value. Figure 6 describes the crushing value of RA $(9.5 \mathrm{~mm})$ before and after chemical enhancement, which confirmed that all the enhancing-technologies can reduce the crushing value of RA. Crushing value is to evaluate the ability to resist crushing. The smaller the value is, the stronger the crushing capacity is. Compared with the original aggregate, the crushing values of RA treated by C-3, C-7, N-P, and $\mathrm{H}$ method were reduced by $11.5 \%, 7.6 \%, 3.3 \%$, and $6.9 \%$, respectively. In the C-3 and C-7 method, the cement mortar filled the pores and bonded the microcracks, thus improving the mechanical properties of RA. The reason why the crushing value of C-3 is lower than that of C-7 may 


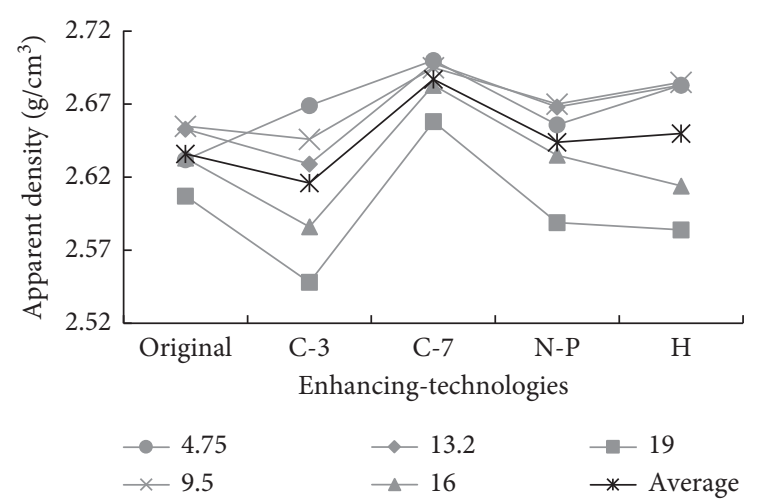

Figure 4: Average value of apparent density of RA before and after chemical enhancing-technology.

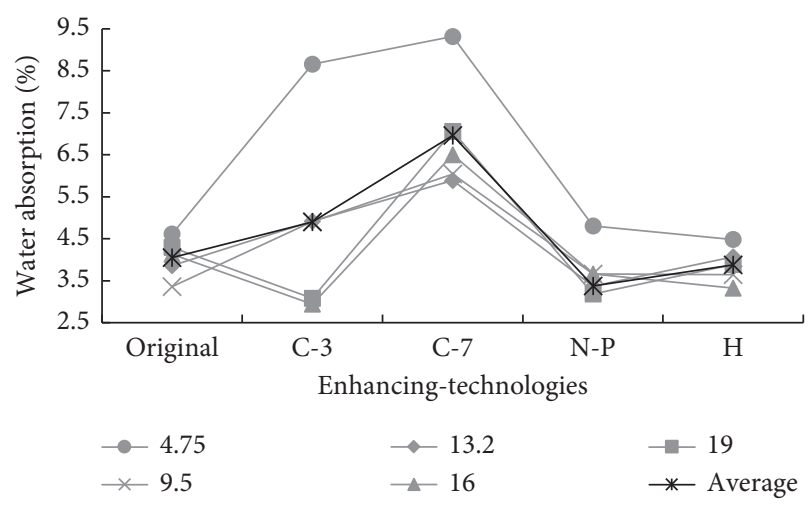

FIGURE 5: Average value of water absorption value of RA before and after chemical enhancing-technology.

be due to the short curing time, less cement hydration products adhered to the aggregate surface, and more hydration products remained to close the voids and cracks. In the N-P method, the alkaline substance reacted with the incompletely hydrated mineral in the RA; then, the product was immersed into the gap of RA, which played a filling role to adhere the microcracks, increasing the strength of RA [26]. At the same time, PVA had good adhesiveness, which can fill pores and microcracks and improve the mechanical properties of RA [27]. In the $\mathrm{H}$ method, $\mathrm{H}_{2} \mathrm{SO}_{4}$ can effectively remove the cement mortar attached to the surface and improve the crushing performance of RA [28].

3.4. Abrasion Value. Figure 7 presents the abrasion values of RA $(16 \mathrm{~mm})$ before and after chemical enhancing-technology. It can be found that the abrasion values decreased in different degrees. The abrasion value is used to evaluate the resistance of coarse aggregate to friction and impact. The smaller the value is, the stronger the resistance to friction and impact is. Compared with the original aggregate, the abrasion values of RA treated by C-3, C-7, N-P, and $\mathrm{H}$ method were reduced by $8.3 \%, 1.9 \%, 4.6 \%$, and $5.4 \%$, respectively. C-3 method and C-7 method were used to repair the weak cement paste on the surface of the original aggregate. The reason why $\mathrm{C}-3$ has a lower abrasion value than C-7 may be due to the short curing time, less cement

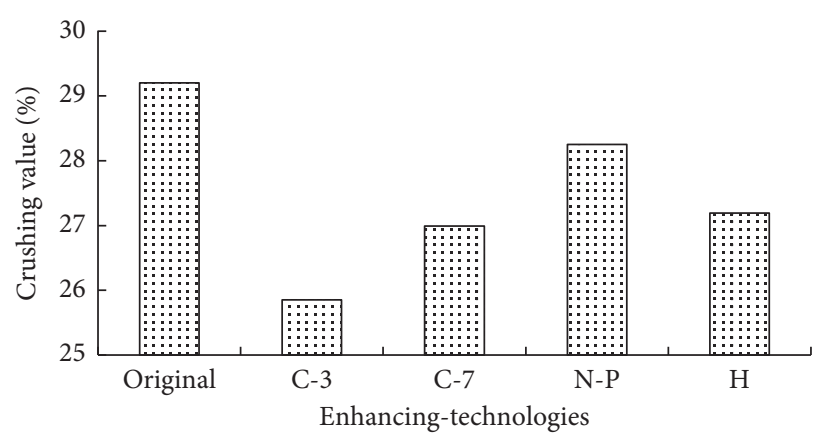

Figure 6: Crushing value of RA before and after chemical enhancing-technology.

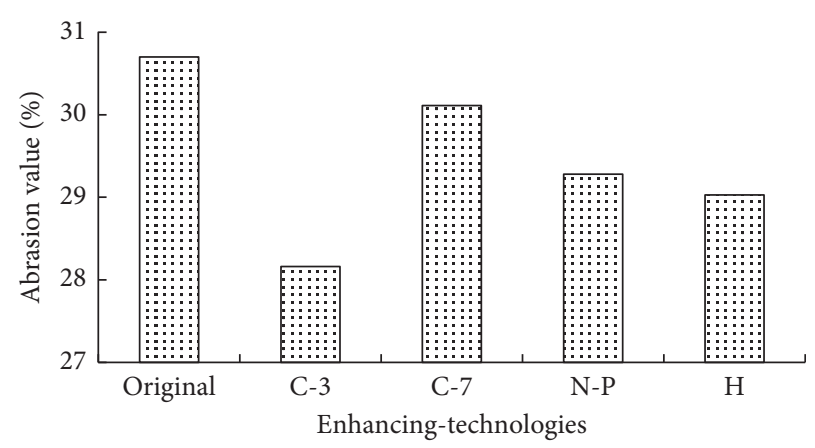

Figure 7: Abrasion value of RA before and after chemical enhancing-technology.

hydration products adhered to the aggregate surface, and the remaining hydration products play a role in closing the gaps and cracks. In the N-P method, on the basis of alkali solution corroding the cement mortar on the RA surface, PVA solution was used to repair the pores and microcracks of aggregate. $\mathrm{H}$ method was to remove the weak layer [29]. The results showed that the repair and removal principles of the four enhancements were different, but the abrasion resistance of RA had different amplitude improvement.

\subsection{AIMS}

3.5.1. Angularity (GA). The morphology of aggregate before and after chemical enhancing-technology can be fully expressed in terms of angularity by using aggregate imaging measurement system (AIMS). Angularity describes the edge sharpness of aggregate particles, which is expressed by GA calculation. The smaller the value is, the worse the angularity is. When the aggregate is circular, GA is equal to zero. The angularity of five kinds of aggregate after Los Angeles abrasion is shown in Figure 8. It can be seen from Figure 8 that the angularity decreased in different degrees. Compared with the original aggregate, the angularity of RA treated by C-3, C-7, N-P, and H method was reduced by $10.2 \%, 9.9 \%$, $4.6 \%$, and $12.8 \%$, respectively. The coating of cement mortar made the aggregate surface more well-distributed, while the sulfuric acid removed part of cement mortars and improved the surface regularity. In contrast, chemical enhancement had a more significant effect on the angularity of the 


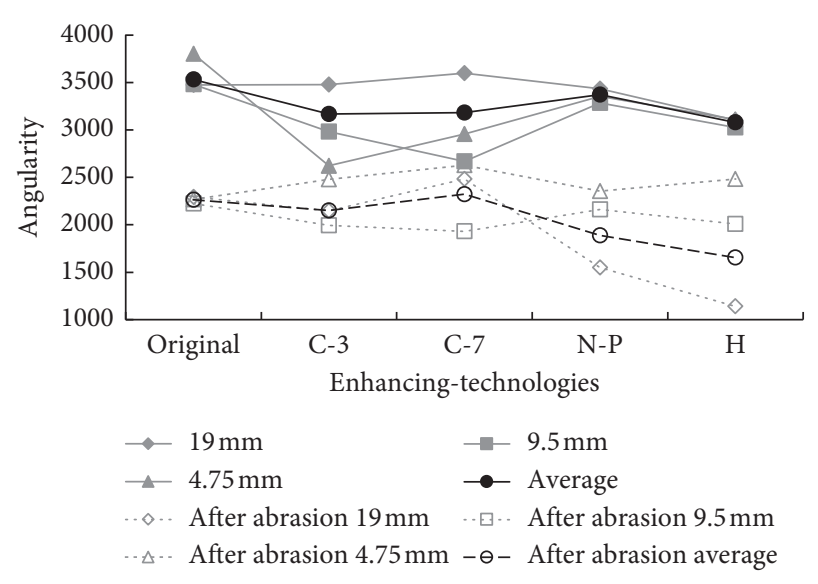

FIgURE 8: Angularity of RA before and after chemical enhancingtechnology.

aggregate with smaller particle size, because the change of the surface state of the smaller particle size made more obvious influence on the overall rule degree.

After abrasion, the irregular part of aggregate caused abrasion loss, which led to the decrease of angularity. At the same time, it is also found that the RA abrasion had less reduction on angularity after C-3 and C-7 method, while $\mathrm{N}-\mathrm{P}$ and $\mathrm{H}$ method had a relatively large reduction. The analysis certificated that the hardened cement mortar on the aggregate surface had a good antiwear effect. In the meantime, the performance of $19 \mathrm{~mm}$ size aggregate was more prominent, because the large size of the aggregate was more impacted in the Los Angeles abrasion.

3.5.2. Texture (TX). The texture expresses the relative surface roughness of aggregate particle. The smoother the aggregate surface, the closer the value to zero. The method was used to precisely detect the texture of aggregates by AIMS, and the results are revealed in Figure 9. As a whole, the texture was reduced by all the enhancing-technologies, and the improvement effect of C-7 method was the best, followed by $\mathrm{C}-3$ method and $\mathrm{H}$ method, while the improvement effect of N-P was the weakest. In relation to the original aggregate, the textures of RA treated by C-3, C-7, N-P, and $\mathrm{H}$ method were reduced by $57.2 \%, 57.8 \%, 4.9 \%$, and $27.5 \%$, respectively. The principal factor was the cement mortar, which filled and covered the aggregate surface, thereby slicking the surface smoothly.

After abrasion, the texture of RA increased, especially after the enhancement of C-3 and C-7 method, which illustrated that the microabrasion resistance of hardened cement mortar was insufficient, while RA treated by N-P method had a fine microabrasion resistance. Thus, the texture of aggregate with different particle size tended to approach after abrasion.

3.5.3. Sphericity (SP). Sphericity describes the overall 3dimensional form of aggregates, which has a value of 0 to $1 ; 1$ indicates a particle has equal dimensions. Figure 10 is an exhibition of the sphericity of RA measured by AIMS. The

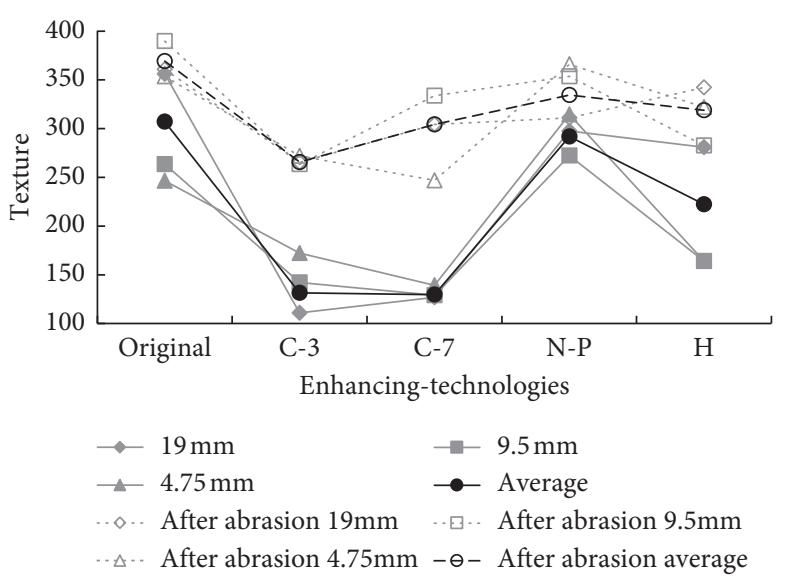

FIgURE 9: Texture of RA before and after chemical enhancingtechnology.

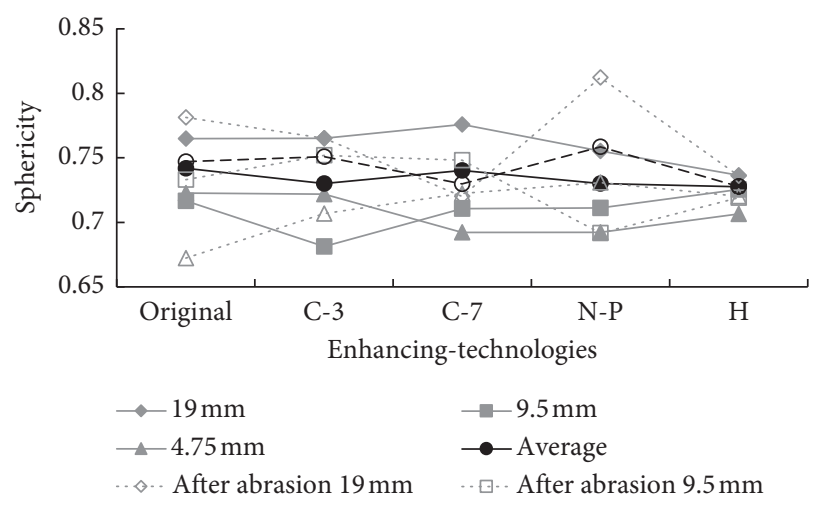

FIGURE 10: Sphericity of RA before and after chemical enhancingtechnology.

influence of the four chemical enhancing methods on the sphericity value of RA was small, and the change regulation of the sphericity was not obvious. Compared with the original aggregate, the C-3 method, C-7 method, N-P method, and $\mathrm{H}$ method reduced the sphericity by $1.6 \%$, $0.2 \%, 1.6 \%$, and $1.9 \%$, respectively. This is because the four enhancements were all in the form of film, which had limited influence on the overall shape of RA.

The four enhancing-technologies have little effect on the sphericity index of RA, and the average value difference of sphericity index is not more than 0.2 . This is because the enhancements play a role in the form of film, which has little effect on the overall shape of RA. However, the difference of sphericity index of RA with different enhancing methods increased after abrasion.

3.6. SEM. The microstructure of the RA was studied by SEM, and Figures 11(a)-11(d) are SEM images of the RA by different chemical enhancing-technology magnified 500 times, respectively. From Figure 11(a), the surface structure of RA treated by C-3 method is the most obvious, and the surface is covered unevenly, which is due to the short curing time of cement mortars, the hydration reaction is not sufficient, and the RA has not formed a 


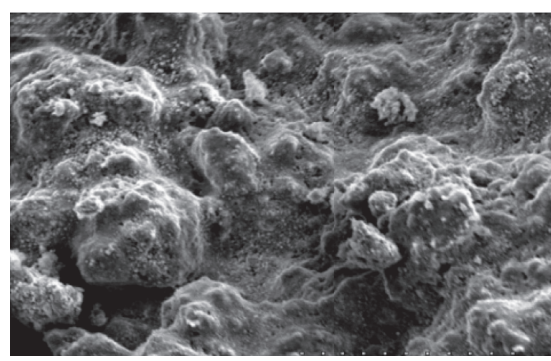

(a)

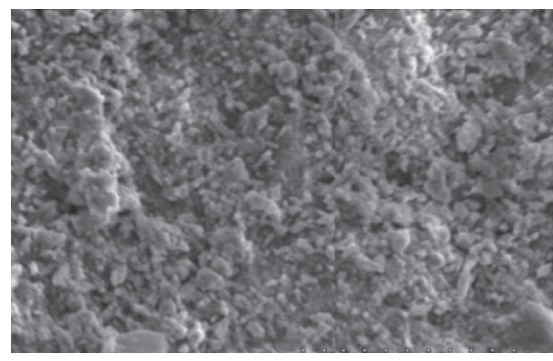

(c)

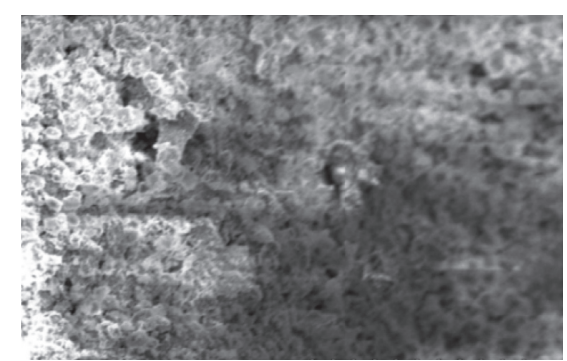

(b)

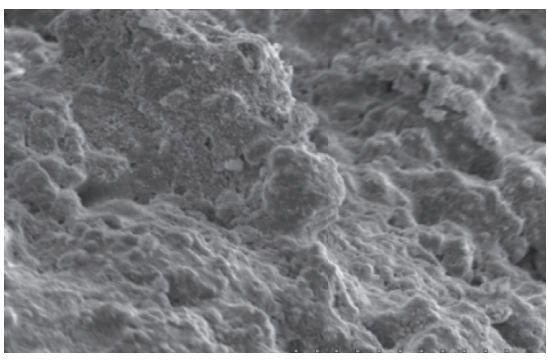

(d)

Figure 11: SEM pictures of RA (500x). (a) C-3 method. (b) C-7 method. (c) N-P method. (d) H method.

good binding. As can be seen from Figure 11(b), there are more crystalline particles on the surface structure of RA treated by C-7 method, which is the result of cement mortars coating on the RA surface [30], forming hydration products such as $\mathrm{C}-\mathrm{S}-\mathrm{H}$ and calcium hydroxide, thereby repairing the original aggregate pores. The $\mathrm{NaOH}$ solution of N-P method reacts with the weak cement mortars on the RA surface, thus the cement mortars is removed. After PVA enhancing, the Si-O-Si and $\mathrm{Al}-\mathrm{O}-\mathrm{Al}$ bonds are destroyed; at the same time, silicate and PVA react on the surface of RA, which makes the hydration products adhere to the surface of RA [24]. It is found from Figure 11(c) that there are a lot of fine particles on the surface of RA, which proved that N-P method can repair the pores and cracks of RA and make the RA surface compact. Analysis of Figure 11(d) discovers that there are obvious voids and structures on the surface of RA. This is due to the erosion of sulfuric acid, which causes many small holes on the surface of RA, damages the aggregate, and affects the compactness of RA surface [31]. The results of micrograph analysis verify that there are significant differences in the microstate of RA surface with different chemical enhancingtechnology.

\section{Conclusions}

This paper evaluated the effects of four chemical enhancing-technologies of RA. The physical properties of RA were studied, including apparent density, crushing value, water absorption, and abrasion value. AIMS was used to quantify the morphological characteristics. The microstructure of RA was monitored by SEM. Based on the above results, the following conclusions can be drawn:
(1) The four chemical enhancing-technologies have obvious influence on the physical properties of RA, but the trend and range vary with the specific methods. As a whole, the apparent density of RA increased after enhancing; meanwhile, the water absorption increased by C-3 method and C-7, but decreased by N-P method and $\mathrm{H}$ method. The discrepancy in physical performances of RA is mainly due to the different mechanism of chemical enhancing.

(2) The mechanical properties of RA were improved by the chemical enhancements, such as crushing value and abrasion value. C-3 method is the most significant method to strengthen the mechanical properties, followed by $\mathrm{H}$ method.

(3) Chemical enhancements have influence on the shape of RA, which will slightly reduce the angularity index and sphericity index, but have significant influence on the texture index. C-3 method and C-7 method can make RA surface smooth obviously, while N-P method has the least effect on texture index. After abrasion, the angularity index of RA decreased, but the texture index increased significantly, and the difference of texture index of different enhancements decreased significantly.

(4) SEM results show that the RA surface structures by C-3 method and $\mathrm{H}$ method are large, but there are a lot of fine structures on the RA surface by C-7 and $\mathrm{N}-\mathrm{H}$ method.

(5) Different chemical enhancing-technologies have different effects on the performance of RA, which should be determined according to the engineering needs and economic costs. However, it should be noted that, after chemical enhancing, the 
fluctuation of RA performance tends to increase, so it is necessary to pay attention to the control of the fluctuation range of RA property in the engineering.

\section{Data Availability}

All the data in this paper are checked, which are obtained from tests in this study, and no other data were used to support this study.

\section{Conflicts of Interest}

The authors declare that, with regard to the publication of this paper and the funding for publishing it, there are no conflicts of interest.

\section{Acknowledgments}

This research was financially supported by the National Natural Science Foundation of China (51878075), Guangxi Natural Science Foundation (2018GXNSFAA294146), Open Fund of Hunan International Scientific and Technological Innovation Cooperation Base of Advanced Construction and Maintenance Technology of Highway (Changsha University of Science \& Technology, kfj190801), the Natural Science Foundation of Hunan Province (2020JJ5595), Guangxi Major Science and Technology Project (Gui Ke AA18242032), and Guangxi Major Science and Technology Project (Gui Ke AB19245019).

\section{References}

[1] J. Zhang, C. Shi, Y. Li, X. Pan, C.-S. Poon, and Z. Xie, "Performance enhancement of recycled concrete aggregates through carbonation," Journal of Materials in Civil Engineering, vol. 27, no. 11, p. 7, 2015.

[2] H. K. A. Al-Bayati, P. K. Das, S. L. Tighe, and H. Baaj, "Evaluation of various treatment methods for enhancing the physical and morphological properties of coarse recycled concrete aggregate," Construction and Building Materials, vol. 112, no. 1, pp. 284-298, 2016.

[3] K. Pandurangan, A. Dayanithy, and S. Om Prakash, "Influence of treatment methods on the bond strength of recycled aggregate concrete," Construction and Building Materials, vol. 120, no. 1, pp. 212-221, 2016.

[4] C. Shi, Y. Li, J. Zhang, W. Li, L. Chong, and Z. Xie, "Performance enhancement of recycled concrete aggregate-a review," Journal of Cleaner Production, vol. 112, no. 1, pp. 466-472, 2016.

[5] E. Ohemeng and E. Stephen, "A review on re-activation of hardened cement paste and treatment of recycled aggregates," Magazine of Concrete Research, vol. 6, no. 1, pp. 1-41, 2019.

[6] B. Kathy, T. Solène, B. Florent, N. Lippiatt, and Y. Ménard, "Assessment of a microwave-assisted recycling process for the recovery of high-quality aggregates from concrete waste," International Journal of Mineral Processing, vol. 126, no. 1, pp. 90-98, 2014.

[7] S. Braymand, S. Roux, H. Fares, K. Déodonne, and F. Feugeas, "Separation and quantification of attached mortar in recycled concrete aggregates," Waste and Biomass Valorization, vol. 8, no. 5, pp. 1393-1407, 2017.
[8] K. K. Wichrowska, P. Edyta, and B. Micha, "Waste-free technology for recycling concrete rubble," Construction and Building Materials, vol. 234, Article ID 117407, p. 13, 2019.

[9] V. W. Y. Tam, C. M. Tam, and K. N. Le, "Removal of cement mortar remains from recycled aggregate using pre-soaking approaches," Resources, Conservation and Recycling, vol. 50, no. 1, pp. 82-101, 2007.

[10] H.-S. Kim, B. Kim, K.-S. Kim, and J.-M. Kim, "Quality improvement of recycled aggregates using the acid treatment method and the strength characteristics of the resulting mortar," Journal of Material Cycles and Waste Management, vol. 19, no. 2, pp. 968-976, 2017.

[11] S.-C. Kou and C.-S. Poon, "Properties of concrete prepared with PVA-impregnated recycled concrete aggregates," $\mathrm{Ce}$ ment and Concrete Composites, vol. 32, no. 8, pp. 649-654, 2010.

[12] V. Spaeth and A. D. Tegguer, "Improvement of recycled concrete aggregate properties by polymer treatments," International Journal of Sustainable Built Environment, vol. 2, no. 2, pp. 143-152, 2014.

[13] T. Liu, Z. Wang, D. Zou, A. Zhou, and J. Du, "Strength enhancement of recycled aggregate pervious concrete using a cement paste redistribution method," Cement and Concrete Research, vol. 122, no. 1, pp. 72-82, 2019.

[14] Y. X. Guo, Q. Y. Li, and W. Q. Wang, "Research on recycled coarse aggregate quality of enhancement technology," Concrete, vol. 6, no. 1, pp. 134-138, 2015.

[15] S. C. Kou and C. S. Poon, "Enhancing the durability properties of concrete prepared with coarse recycled aggregate," Construction and Building Materials, vol. 35, no. 1, pp. 69-76, 2012.

[16] T. Y. Chen, The Influence of Reinforced Recycled Coarse Aggregates on the Mechanical Performance and Durability of Recycled Concrete, Harbin Institute of Technology, Harbin, China, 2016.

[17] W. M. Shaban, J. Yang, H. Su et al., "Properties of recycled concrete aggregates strengthened by different types of pozzolan slurry," Construction and Building Materials, vol. 216, no. 1, pp. 632-647, 2019.

[18] N. K. Bui, T. Satomi, and H. Takahashi, "Mechanical properties of concrete containing $100 \%$ treated coarse recycled concrete aggregate," Construction \& Building Materials, vol. 163, pp. 496-507, 2018.

[19] J. J. Chen, J. J. Thomas, and H. M. Jennings, "Decalcification shrinkage of cement paste," Cement and Concrete Research, vol. 36, no. 5, pp. 801-809, 2006.

[20] B. Zhan, C. S. Poon, Q. Liu, S. Kou, and C. Shi, "Experimental study on $\mathrm{CO}_{2}$ curing for enhancement of recycled aggregate properties," Construction and Building Materials, vol. 67, no. 1, pp. 3-7, 2014.

[21] C. Shi, Z. Wu, Z. Cao, T. C. Ling, and J. Zheng, "Performance of mortar prepared with recycled concrete aggregate enhanced by $\mathrm{CO}_{2}$ and pozzolan slurry," Cement and Concrete Composites, vol. 86, no. 1, pp. 130-138, 2018.

[22] C. Moro, V. Francioso, and M. Velay-Lizancos, "Nano- $\mathrm{TiO}_{2}$ effects on high temperature resistance of recycled mortars," Journal of Cleaner Production, vol. 263, Article ID 121581, a, p. $12,2020$.

[23] G. S. Kumar, "Synergetic effect of a chemical activator and blast-furnace slag on enhancing recycled aggregate mortar," Journal of Technology, vol. 72, no. 9, pp. 471-485, 2020.

[24] X. Q. Hua, Strengthening Research on Building Waste's Recycled Aggregate Concrete, Kunming University of Science and Technology, Kunming, China, 2009. 
[25] J. H. Wang, O. Geng, and F. M. Li, "Experiment on effect of several measures by modifying recycled coarse aggregate on improving compressive strength of concrete," Journal of Architecture and Civil Engineering, vol. 33, no. 2, pp. 91-97, 2016.

[26] X. H. Hu, J. Xiao, and H. P. Yang, "Experimental research on chemical strengthening of recycled coarse aggregate," Journal of China \& Foreign Highway, vol. 39, no. 1, pp. 256-260, 2019.

[27] L. L. Han, Experimental Study on Modification of Recycled Aggregate and Concrete Properties with Construction Waste, North China University of Water Resources and Electric Power, Zhengzhou, China, 2019.

[28] T. Li, "Influence of Defects in Recycled Aggregate on Mechanical Properties of Recycled Aggregate Concrete, Beijing Jiaotong University, Beijing, China, 2013.

[29] H.-S. Kim, J.-M. Kim, and B. Kim, "Quality improvement of recycled fine aggregate using steel ball with the help of acid treatment," Journal of Material Cycles and Waste Management, vol. 20, no. 2, pp. 754-765, 2018.

[30] M. Malešev, R. Vlastimir, and V. Suzana, "Influence of fly ash and decreasing water-powder ratio on performance of recycled aggregate concrete," Građevinar, vol. 69, no. 9, pp. 811820, 2017.

[31] V. W. Y. Tam, C. M. Tam, and K. N. Le, "Removal of cement mortar remains from recycled aggregate using pre-soaking approaches," Resources, Conservation and Recycling, vol. 50, no. 1, pp. 82-101, 2007. 